\title{
EL RESCATE DEL ETHOS DE LA POLÍTICA EN LA SOCIEDAD ACTUAL Alejandro Ordoñez Maldonado
}

\section{Introducción}

Estar hoy aquí en la Universidad de Salerno, que junto con la de París y la de Bolonia son las más antiguas de Europa, recibiendo de ella un alto honor que benevolentemente me otorga la comunidad académica por manos del Excmo. Sr. Rector, despierta en mí, además del agradecimiento emocionado y profundo, un enorme compromiso con mi país, en razón de mi condición de Procurador General de la Nación, a quien por mandato de la Constitución de Colombia le corresponden, como «Supremo Director del Ministerio Público», las funciones de «vigilar el cumplimiento de la Constitución, las leyes, las decisiones judiciales y los actos administrativos», "proteger los derechos humanos y asegurar su efectividad»y «defender los intereses de la sociedad». A esta tarea he dedicado todas mis fuerzas, desde que fui nombrado en el año 2008 por el Honorable Senado de la República. Este inmenso honor incrementa mi deseo de estar siempre a la altura de esa responsabilidad y me estimula, fortalece y llena de esperanza sobre el futuro del país. Tal vez ustedes estén esperando una disertación sobre los problemas de Colombia, con apoyo en estadísticas de corrupción o de muerte. Sin embargo, por el singular sentido que encierra este solemne acto académico, quiero referirme al trasfondo cultural, social y político que permite entender el porqué de nuestro drama histórico. El punto de partida de esta reflexión es la situación de mi patria, considerada a partir de la perspectiva desde la cual me ha sido dado pensarla y 
enfrentarla, es decir, mi experiencia al frente del Ministerio Público y mis largos años como juez, magistrado y consejero de Estado, así como desde mis convicciones intelectuales, acendradas durante treinta años de ejercicio de la cátedra universitaria. De ahí que haya querido denominar estas palabras «El rescate del ethos político en la sociedad actual».

\section{El ethos político de una sociedad en conflicto}

Vivimos en sociedades en conflicto: no es un problema exclusivo de mi patria, lo es de esta mi querida y admirada Italia, con la cual tantas cosas nos unen. Y es también un problema mundial. Si algo caracteriza a la sociedad actual es el ser enormemente conflictiva. No me refiero a los problemas engendrados por la complejidad inherente a su estructura y evolución en el tiempo. Hablo de factores que amenazan seriamente su gobernabilidad. Basta mencionar la violencia generalizada y el fenómeno de la corrupción tan extendido. Por doquier hay conflictos en el Estado, en el gobierno, en la política, en la sociedad civil, en la empresa, en la educación, en la familia y en las personas, cuyos efectos se manifiestan en forma permanente. Ante esa situación, podría sonar como idealista aunque cierta, aplicada a la sociedad de hoy, la conocida definición de San Agustín: «Pueblo es el conjunto multitudinario de seres racionales asociados en virtud de una participación concorde en las cosas que aman» (1). Parecería que ese maravilloso ideal se disolviera en la vorágine conflictiva de la sociedad contemporánea cuyo ethos polí tico quisiéramos ayudar a rescatar para que pueda responder a las expectativas del pueblo que la integra.

La política, como ciencia de la filosofía práctica debe propender por el bien común. Tan ambiciosa meta, nos ofrece hoy unos contrastes alarmantes, al menos en la sociedad colombiana, pues desafortunadamente hoy la prosperidad de la nación se mide más en términos financieros y contables que éticos.

(1) De Civitate Dei, XIX, 24: «Populus est coetus multitudinis rationalis, rerum quas diligit concordi ratione sociatu». 
A tal desviación del fin querido por la política contribuye la dictadura del libre mercado que la ha convertido -como afirman autores italianos (2) - en una especie de mandato constitucional en cabeza de la Organización Mundial del Comercio. Esa dictadura, que se ejerce, paradójicamente, dentro del sistema democrático, abre las puertas a la inequidad social. En Colombia esto es bastante patente: con un coeficiente Gini de 0.57 en el año 2010, el país se coloca entre los más altos del mundo en desigualdad social, por contraste con los avances económicos logrados en las últimas décadas. La política, por su propia esencia de búsqueda del bien común a través del ejercicio del poder, debe ir más allá de la economía (3).

Desde el punto de vista de lo que llamamos aquí el ethos de la política, nos encontramos palpable en los grandes países desarrollados, y también entre los países emergentes o en vías de desarrollo, con una dicotomía entre la cultura de los derechos y la cultura de los deberes, en detrimento de estos últimos. Como si exigir el cumplimiento de los primeros fuera sólo obligación del Estado, y los segundos quedaran en manos de la buena voluntad de los individuos. Un caso colombiano que ilustra bien este punto es el relativo a las consecuencias que las normas constitucionales sobre libre desarrollo de la personalidad, y las interpretaciones normativas que se le han dado, han abierto un torrente de abusos y desafueros. Entonces el derecho, en lugar de fortalecer, debilita las instituciones y las personas mismas, como ha ocurrido con los cambios en la legislación sobre la familia, cuyas estadísticas indican una progresiva desintegración. No sólo las normas deben regir la sociedad; también los principios éticos que no dependen de los mecanismos electorales, los cuales son garantía para una justa convivencia.

Otro aspecto que quisiera señalar es que la política y los gobiernos están en serio déficit con las necesidades prioritarias de la sociedad, y eso lleva a que la ciudadanía se sienta

(2) Cfr. Monica Di Sisto, Roberto Bosio y Alberto Zoratti, Dalla dit tatura del mercato alla democrazia mondiale, Bolonia, EMI, 2005.

(3) Cfr. Henri Hude, Philosophie de la prospérité. Marché et solidarité, París, Editions de Prologue, 1994. 
engañada. Las movilizaciones políticas de diversas banderas partidistas o de grupos sociales afectados, están a la orden del día, y son fuente de perturbación social permanente. De ahí que no resulta extraño que, por ejemplo, un movimiento como el de «los indignados», surgido en Europa en años recientes, se asome en diferentes formas en nuestras latitudes. O que el movimiento estudiantil surgido en Chile hace pocos años tenga un eco inmediato en otros países latinoamericanos, entre ellos Colombia, donde logró frenar el año pasado la reforma de la educación superior propuesta por el gobierno. En el país tiene una marcada significación política todo lo relacionado con los desplazados por la guerrilla, el paramilitarismo, las bandas criminales, el narcotráfico y el terrorismo. Son ya varios millones de personas con un inconformismo profundo frente al Estado y los gobiernos, lo que lleva a pensar que hay que buscar no sólo nuevas soluciones sino nuevas formas de hacer política.

En cierta manera, en nuestra sociedad, se evidencia el fracaso de las ideologías que han inspirado la política del mundo en los últimos siglos: la teoría del liberalismo surgido en la revolución francesa, el marxismo en sus diferentes formas de socialismo y comunismo, y el capitalismo que domina el acontecer político en buena parte de las sociedades actuales. Allí penetra con fuerza la ideología de la globalización, que se presenta como el tren de la victoria, como la gran fuente de las soluciones, pero estamos ante el mismo signo antes mencionado de la subordinación total de la persona al Estado, al punto de desnaturalizarla (4).

No es extraño que todos los aspectos antes mencionados produzcan un profundo desencanto frente a todas las ideologías políticas y al sistema de partidos vigente. Sin olvidar que hay dos fenómenos que operan como dos cánceres que radicalizan los problemas y la inconformidad en forma que amenaza directamente la gobernabilidad del Estado y la institucionalidad de las estructuras de legalidad en ella: la violencia y la corrupción. No pretendo extenderme aquí sobre

(4) Juan Pablo II, Discurso a la Academia Pontificia de Ciencias Sociales, 27 abril 2001: el riesgo es que se convierta en «una nueva forma de colonialismo». 
ellas, pero si debo recalcar que sus dimensiones ponen en vilo la seguridad del país, su credibilidad y fortaleza. También el ethos de la política es alterado por estos fenómenos. Puedo decir hoy aquí, que una parte significativa de mi tarea al frente del Ministerio Público se consume en la implacable lucha contra los corruptos, ante la cual, en ciertos momentos, lo he afirmado con dolor, constato la impotencia del Estado y de sus mecanismos de control que son desbordados por el delito. Los cánceres de la violencia y la corrupción ponen en evidencia, particularmente, las debilidades del sistema de justicia y reflejan el vacío de la falta de una ética pública arraigada en la cultura de las instituciones del Estado. Sabemos que el Estado no puede sucumbir, pero esta situación puede hacer nugatorios sus esfuerzos por restaurar el tejido social roto por la falta de paz.

¿Y qué decir de la situación del ser de las personas, de cómo este drama afecta a cada uno de los ciudadanos en su búsqueda inevitable del bienestar, de la calidad de vida o, en pocas palabras, de su felicidad? El hecho de que la mayoría de la gente piense ante todo en el éxito como algo ligado únicamente a la seguridad material refuerza, una vez más, el predominio de lo económico en la política. La educación se limita a ser productiva materialmente y en apuntarle al mejor ingreso posible. Ahí la persona es la gran perdedora. Hay una secuencia que arranca en el predominio del tener sobre el ser, en una palabra: del materialismo, a cuyo amparo se cultiva el individualismo, con un falso sentido de la autonomía y con el olvido de lo colectivo, lo cual puede derivar en el relativismo ético y en la violencia y la anarquía social (5). La educación forma buenos consumidores, algunos de ellos violentos, cosa que se palpa con el auge del bull ying o matoneo escolar. Las enfermedades psicológicas aumentan a pesar del mayor ingreso individual, como lo demuestran las investigaciones sobre la felicidad en las sociedades actuales (6). La familia, el ámbito natural de la persona, está siendo prácticamente destruida por las leyes

(5) Cfr. José PÉrez AdÁn, Repensar la familia, Madrid, EIUNSA, 2005.

(6) Cfr. Richard LAYARD, La felicidad, lecciones de una nueva ciencia, Madrid, Taurus, 2005. 
permisivas (divorcio, aborto, eutanasia, y formas de familia que no concuerdan con su diseño natural).

En general, se recorta el ámbito de acción de las personas, se empobrecen las relaciones sociales, se afectan la identidad cultural, el patriotismo y el civismo, se descuidan la historia y las tradiciones culturales, los valores religiosos y la ética, todos ellos, referentes importantes que ofrecen a las personas una orientación para la conducta. Las personas se vuelven vulnerables a la vida fácil, a la renuncia al sacrificio, y a la falta de ciudadanía participativa y comprometida con el bien del país. Y lo que pervive de la moral, se torna algo confuso, en cuya interpretación juegan el papel desorientador de los medios de comunicación, que ejercen una especie de hipoteca sobre la sociedad. Se abandona la formación moral del individuo y su plena inserción en la comunidad. Y la sociedad -que no puede existir sin la familia y sin personas que puedan desarrollarse integralmente- se convierte en una inmensa caravana de solitarios que va camino de ninguna parte $(7)$.

\section{Fortalecer la institucionalidad en la cultura de la legalidad}

Colombia necesita una sociedad civil fuerte y operante para restaurar el ethos de la política y lograr hacer de ella auténtica comunidad humana. Comunidad, comunicación y participación derivan de la misma raíz etimológica (koinonía que significa comunión, puesta en común). Esto nos recuerda que la socialidad tiene raíces ontológicas que no se pueden dejar de lado porque nos permiten entender porqué las personas están hechas para convivir con los demás. La auténtica comunidad se forma cuando las libertades individuales se sujetan al común bienestar de los hombres, en cuanto a hombres (8). En palabras sencillas, cuando se procura por el respeto de su orden natural y se busca su perfección social con esos limites.

(7) Helmut KuHN, citado por Josef Ratzinger en Verdad, valores y poder, Madrid, Rialp, 1995.

(8) Alain Touraine, Qué es la democracia, Madrid, Temas de hoy, 1994. 
La sociedad, se realiza en sus instituciones: la familia como primera escuela de la solidaridad; las empresas como ámbitos necesarios para impulsar la economía y la productividad; las instituciones educativas como ámbitos de la formación para el trabajo productivo y para la vida social; las instituciones asistenciales, o culturales, que cumplen objetivos complementarios e indispensables; y la instituciones políticas y jurídicas que obran con autoridad reguladora de las diferentes instancias. Para que de verdad las instituciones orienten su actividad al bien común, no a los intereses particulares, deben acatar una ley común, deben poseer tareas comunes, ofrecer resultados comunes y tener una vida y unas relaciones comunes. Una forma de fortalecer las instituciones es teniendo en claro que la política es para servir a la sociedad, no para servirse de ella. Que su acatamiento viene dado por la eticidad que despierta la virtud de la obediencia de los gobernados. Por eso, Aristóteles fundamenta el deber de obediencia a la ley en el ethos (9). El ethos de la política hunde sus raíces en la naturaleza humana que sigue unas reglas de conducta esenciales inscritas en el ser, que no dependen de las variables circunstancias de las ideologías políticas. En ese sentido se trata de algo universal, no globalizado como fruto de consensos partidistas (10).

Como ha expuesto Robert Spaemann (11), se trata de reglas universales que debe seguir cualquier hombre razonable si no quiere hacer disparates. El ethos moral no es resultado de un proyecto sino algo inscrito en la naturaleza humana, lo cual le da un sentido perenne, universal e inmutable. Junto a ese ethos fundamental, el mundo sin duda dispondrá de otros referentes condicionados por la época. Pero sin lo primero, se convertiría en relativismo ético.

En el caso de la sociedad colombiana teníamos hace unas décadas una ética de orientación católica que se ha perdido pero no ha sido remplazada por nada, es decir, las

(9) Aristóteles, Política, II, 8, 1269, a 20.

(10) Amitai Etzioni, La nueva regla de oro. Comunidad y moralidad en una sociedad democrática, Buenos Aires, Paidós, 1999. 2007.

(11) Robert Spaemann, Ética, política y cristianismo, Madrid, Palabra,

Verbo, núm. 507-508 (2012), 533-547. 
personas y las instituciones navegan sin horizonte moral, al compás de lo que les dicta el relativismo o la indiferencia ética. O de lo que beben en la fuente contaminada de una política en la que predomina la legalidad sin cultura ética, el cumplimiento de las leyes desprovistas del acompañamiento de los valores. De ahí que haya resultado inspirador para nuestra tarea al frente del Ministerio Publico en Colombia, desde el comienzo de nuestra gestión, la tesis italiana de Leo Lucca Orlando, con su teoría sobre el estrecho vínculo entre legalidad y cultura, puesta en acción para recuperar la identidad de la sociedad siciliana secuestrada por la mafia, política exaltada por la ONU como un paradigma de la lucha anticorrupción en el mundo. Hemos contado incluso con su presencia en Colombia como un testimonio fehaciente de que es posible restaurar el ethos de la política devolviendo a la comunidad lo que por esencia le pertenece. Él nos recuerda que «cultura es en primer lugar, la conciencia de la identidad individual y comunitaria y su relación con respecto al ser humano» (12). Estamos trabajando con ahínco en esa cultura, inseparable de la promoción de la moralidad pública. Después de tres generaciones sin formación ética hemos logrado que la sociedad adquiera conciencia de la necesidad y la urgencia de la cultura ética en lo público. Queremos una Colombia con la moral en alto, no sólo para contrarrestar la imagen negativa propagada por algunos medios de comunicación, sino porque es una necesidad social vinculada a la recuperación del autoestima como país y a la eficacia de la lucha contra la corrupción.

Hemos dicho que hay que mantener un equilibrio entre la persecución legal de la corrupción y una pedagogía de los valores a nivel social y a nivel del Estado. Es una forma coherente de disminuir la incidencia que la corrupción tiene en la violación de los derechos fundamentales, en la pobreza, en la violencia y en la destrucción de la familia. Tenemos la obligación no sólo de señalar unos parámetros legales para la conducta de los funcionarios sino la de promover valores

(12) Leoluca ORLANDO, El carro siciliano, http://www.sicilianrenaissance.info. 
éticos, así se garantiza la búsqueda del bien común. Las sociedades se degradan moralmente cuando quienes las componen se degradan personalmente y eso se convierte en un contagio, en una enfermedad colectiva. Del mismo modo que la ley es inseparable de la coacción para hacerla respetar, la ética y los valores no se pueden imponer sino proponer para que hagan parte de la cultura de las instituciones del Estado (13). Una muestra de ello es que el Estado colombiano ha promulgado un Manual de gestión ética para las entidades del Estado, que no es otra cosa que una guía para ayudar a los funcionarios públicos a vivir cabalmente, con transparencia, responsabilidad y honestidad su tarea y para fortalecer la cultura de las instituciones públicas.

Obrar así es partir igualmente de una firme y sincera convicción, profundamente afincada en nuestra experiencia de estos años al frente del Ministerio Público, de que las inmensas mayorías de una nación como Colombia están conformadas por gente honesta y trabajadora que anhela vivir en paz y que con su vida demuestran que, a la larga, la acción de los corruptos y los violentos será derrotada.

La cultura de la legalidad, en este contexto, se convierte también en una poderosa herramienta para la búsqueda de la anhelada paz, que ha sido esquiva durante medio siglo para Colombia. Cincuenta años de violencia guerrillera no se arreglan sólo con base en un diálogo. Creemos que la paz no es un requisito previo sino el fruto de un proceso que no necesariamente implica una dilación del diálogo, sino poner ciertas bases que lo hagan discurrir sobre la realidad, no sólo sobre las palabras de un compromiso. Pensamos seguir trabajando denodadamente por el fortalecimiento de una cultura de los derechos fundamentales en el bien común que contribuya a un clima social de respeto a la vida y de promoción de la equidad social que tanto se requiere. Uno de nuestros empeños es demostrar que un organismo de control como el Ministerio Público puede cumplir con eficacia y eficiencia su misión en el marco de la Constitución y la ley, con conciencia de su aporte a la reconstrucción del

(13) Alain Touraine, ibidem. 
tejido social. Colombia entera siente la urgencia de la paz y debemos lograrla como un imperativo que el mundo de hoy exige. Podríamos decirlo acudiendo a la ironía del gran poeta italiano Petrarca al que se le atribuye esta conversación con un loco:

El loco, al ver soldados en marcha, pregunta al poeta:

- «¿Adónde van?»

- «A la guerra», le responde Petrarca.

El loco observa: «¿No es cierto que esta guerra terminará un buen día mediante la paz?»

- «iCierto!», replica el poeta.

Entonces añadió el loco: «¿Por qué no hacen inmediatamente la paz antes de comenzar la guerra?».

Petrarca concluye melancólicamente: «iYo pienso igual que este loco!». Todos pensamos como este loco, y nos decimos, ¿por qué no?

\section{La reconstrucción del ser de la persona desde la familia}

«Toda persona tiene deberes respecto de la comunidad puesto que solo en ella puede desarrollar libre y plenamente su personalidad», se lee en la Declaración Universal de los Derechos Humanos. Dentro de este análisis del ethos de la política actual, nos toca considerar cómo es afectado por la situación de la familia en la sociedad y cómo se puede formar el ser de las personas desde la familia siempre que restauremos su verdadero dinamismo en la comunidad. La inestabilidad del Estado y la debilidad de sus instituciones reflejan de modo patente la inestabilidad de la familia. Según estadísticas actuales, más del $50 \%$ de las familias colombianas están desintegradas a causa del divorcio, de la separación o del abandono de uno de los cónyuges. El 
Estado mismo, parece paradójico, se ha dedicado a destruir la familia. Se facilita su disolución (separación, divorcio exprés, matrimonio homosexual con adopción) se debilita la autoridad de los padres, no se permite el oportuno cuidado de los hijos debido a los horarios laborales, se fomenta la legalización de formas de familia que no responden a su naturaleza fundamental, la educación no se ocupa de formar para la vida familiar.

El hecho mismo de que se busque legalizar uniones que no tienen naturalmente nada que ver con la familia, ni la han tenido históricamente, indica que ella es un ideal válido, desconociendo que «la familia basada en el matrimonio de un hombre y una mujer es reconocida universalmente como un elemento natural y fundamental» (14), es decir, el referente indispensable de la sociedad. Destruyendo la familia como institución, se provoca una ruptura con la propia cultura. Con ello, la nación queda despojada de su identidad, y queda obligada a imitar o adoptar la cultura de otras sociedades. Y cuando eso se hace (por el tipo de modelos anti-familia que penetran la cultura del país) se pierde la identidad, se pierde la razón de ser de la familia y a la larga se pierde la libertad porque son esos modelos foráneos los que deciden el tipo de familia, porque otros países y otras culturas invaden la existencia de la familia. Eso no es otra cosa que un colonialismo destructor. Como afirma Rafael Navarro Valls (15): «Muchos sectores pretenden diseñar hoy una "familia incierta", una especie de "uniones a la carta" en la que se deja a las partes la determinación de sus efectos, duración y fin. Parece como si sesenta generaciones hayan vivido en la noche de la ignorancia hasta que ha comenzado a salir el sol con Morgan, Freud o la ideología de género». Hoy lo que existe es una agenda contra la familia, desde la institucionalidad global y desde los medios de comunicación que se trata de imponer a todos los países al margen de su naturaleza.

Las ideas de familia y matrimonio que naturalmente se evidencian por sí mismas están siendo erosionadas por una

(14) AA.VV., Family as primary educator, Scepter, London.

(15) Rafael NAVARRo VALLs, El matrimonio religioso ante el derecho español, Madrid, Universidad Complutense, 1984.

Verbo, núm. 507-508 (2012), 533-547. 
minoría encriptada en los medios de comunicación o en los escenarios académicos controladas por cierta ideología contra natura. El matrimonio queda reducido a una relación afectiva sexual, a un simple hecho cultural. Lo que logran es que los jóvenes no se interesen en el matrimonio porque pierden libertad, según ellos, para cambiar. Y lo que se pierde es la continuidad de la familia y a la hora de la verdad el proyecto de ellos se vuelve solitario y egoísta, al margen de las necesidades de la comunidad. Si la esencia del matrimonio deja de estar vinculada a la heterosexualidad y se basa exclusivamente en los lazos sentimentales y en la voluntad de convivencia, por analogía pueden caber nuevas formas de unión como el matrimonio plural, ya que el número de personas tampoco tendría que considerarse esencial. Se pretende hoy por el pensamiento políticamente correcto convertir al matrimonio en un vínculo sentimental o sexual y no en la institución responsable de la generación de personas y de su educación. Tenemos que preguntarnos entonces, ¿por qué el ethos político de la sociedad se afecta al afectarse la estructura de la familia como pilar primordial del orden social? Para eso es necesario que consideremos que el Estado debe reconocer y no crear la familia. Es decir, debe aceptar que hay unos principios verdaderos e inmodificables, lo cual implica un rechazo del relativismo, para el cual no hay verdad ni ética.

El Estado no debe promover leyes que atenten contra esos derechos inalienables (16), no debe promover la disolución de la familia al aceptar leyes que trivializan el vínculo matrimonial o dan lugar a supuestas formas de familia que van directamente contra los principios naturales y contra los derechos y la defensa de la dignidad antes proclamada (17). Ello va en contra del reconocimiento que hizo la Carta de la ONU al decir que «la familia es elemento natural y fundamental de la sociedad y tiene derecho a la protección de la sociedad y el Estado» (18).

(16) ONU, Declaración Universal de los Derechos Humanos, primer considerando.

(17) RATZINGER, Verdad, Valores y poder, cit.

(18) ONU, ibidem, artículo 16.1. 
Cabe aquí la admonición de Chesterton: «Quién ataca la familia no sabe lo que hace porque desconoce lo que deshace». Tal vez ese es el llamado que se escuchó en mi País al aprobar una ley marco de la familia que busca «fortalecer y garantizar el desarrollo integral de la familia, como núcleo de la sociedad» (19). Y en ella se dice que la familia es «el núcleo fundamental de la sociedad [...que] se constituye por vínculos naturales o jurídicos, por la decisión libre de un hombre y una mujer de contraer matrimonio o por la voluntad responsable de conformarla». Sin embargo, dicha ley es desconocida por las Cortes, pues a través de sentencias particulares, basadas en reclamaciones de supuestos derechos individuales, cambian la legislación al aprobar decisiones que van directamente contra los principios naturales.

No cabe duda que el Estado no puede remplazar nunca a la familia y si rompe su equilibrio, se rompe el equilibrio del Estado. No hay nada más sólido que lo natural y lo natural en la concepción política de la sociedad es la familia, que forma parte de su ethos esencial (20).

Por eso hay que trabajar sin descanso para que esa protección y defensa sea realidad. Con la seguridad -en palabras de Balzac- de que «en la regeneración de la familia está la base de la regeneración de la sociedad». La familia, es factor clave en la formación para obedecer a la autoridad. Cuando un hermano golpea a otro hermano o a su padre, o a un compañero de colegio, o a un maestro, está preanunciando que no va a obedecer la autoridad del Estado. Es el germen de la violencia y la anarquía. Ahí está ya también amenazada la paz. En ella el ser de las personas empieza a cultivarse, y cada paso es importante. Es el modelo formativo social por excelencia.

Si ponemos en el corazón de la política el bienestar de las familias y la formación de personas para construir comunidades justas y pacíficas, tendremos un norte indefinido y un camino claro para restaurar el ethos de la política en n u e stras sociedades. No me cabe duda de que es necesario y posi-

(19) Ley 1361 de 2009.

(20) RATZinger, Verdad, valores y poder, cit. 
ble pensar así. No es sólo un problema de necesidad o de conveniencia. Es la única salida en una sociedad de individuos incomunicados y aislados, acostumbrados a una cultura de la transgresión -no hay límites pues todo se considera trivial e irrelevante- y a una falta de una cultura de la trascendencia: la que se da en la persona misma que con su voluntad e inteligencia trasciende las circunstancias materiales y lucha por construirse un futuro; la que se da en la práctica de los valores que nos ponen en contacto con los otros y se refrendan en el reconocimiento que de ellos cuando comprueban que hay compromiso, lealtad, responsabilidad o transparencia en la conducta; la que se da en el trato con los demás cuando prima el respeto y la vivencia de una cultura de dar y de servir, de ayudar y ser solidario; la que se da cuando se piensa la patria que se hace realidad a través del aporte de cada uno a la construcción colectiva que llamamos comunidad; la que se da también cuando pensamos que todo lo anterior encuentra una motivación trascendente $(21)$.

No estamos ante la puerta del infierno leyendo la advertencia fulminante del Dante: «voi ch'entrate, lasciate cui ogni speranza» («vosotros los que entráis, dejad aquí toda esperanza») (22): sino que, al contrario, nos inspiran otras palabras del canto poético más grande de la historia de la humanidad: "amor mi mosse, che mi fa parlare» («el amor es lo que me mueve y me hace hablar») (23). Sí, y lo digo con la emoción que siento en este acto, y con la emoción que supone hablar de política en la Academia pensando en la sociedad. El amor, el corazón, me hacen hablar con la esperanza de que desde la Universidad, al preguntarnos sobre el futuro de la sociedad, pensemos en que desde ella se puede llevar a cabo una tarea importantísima en la restauración de la familia, del ser de la persona y del ethos político de nuestra sociedad si trabajamos en mantener vertebrada la sociedad con base en la familia; en que en ella se fortalezcan las per-

(21) Cfr. Nota de la Sagrada Congregación para la Doctrina de la Fe, 24 de noviembre de 2002.

(22) Divina Comedia, «Infierno», canto III, 9.

(23) Divina Comedia, «Infierno», canto II, 70. 
sonas afectiva, intelectual y moralmente; en que sean escuelas de valores, de solidaridad y de participación; en que en ella los hijos sean el mayor tesoro que hay que cuidar y proteger; en que en ella se descubra y se respete el misterio de la vida; en que en ella se aprenda a convivir con los demás venciendo el individualismo; en que ahí se descubra la fuerza de la vida espiritual de las personas y su dimensión trascendente; en que en ella se entienda y se viva que la paz es obra, ante todo, de la caridad y la justicia entre las personas que integran la familia; en que ella sea el lugar por excelencia donde se aprende a querer; en que las familias enseñen a descubrir las virtudes y en que si hacemos familias de verdad, serán renovadoras, mejor aún, formadoras de una nueva sociedad.

Para terminar quisiera, desde esta histórica Universidad, reiterar una fervorosa invitación para que recuperemos el ethos de la verdadera política combatiendo denodadamente el sometimiento del inmanentismo, y teniendo en la política como referente indispensable la recuperación del ser integral de la persona y el respeto y protección jurídica de su ámbito esencial por excelencia, la familia. Eso es posible y es necesario, y lo lograremos. Con la solidaridad generosa de Italia y de la comunidad internacional, Colombia avanzará en el fortalecimiento de su Nación. El drama de violencia que nos ha tocado vivir no es para siempre, y si yo lo he querido recordar con unas pinceladas fuertes en este recinto universitario, ha sido fundamentalmente para agradecer el honor que se me hace, y actuar en esta solemne y memorable ocasión como vocero del pueblo colombiano, y decirles de todo corazón que somos gente de paz, honesta, laboriosa y alegre, que comparte la esperanza de ser para el mundo una sociedad más pacífica y más justa. Tenemos el convencimiento sincero y firme de que esa es nuestra vocación. Y yo, en mi condición de defensor de los intereses de la sociedad, les aseguro que no seremos inferiores a ese clamoroso llamado de la Historia. 